\title{
35 years with an uninvited guest
}

\author{
Fredric L Frye DVM FIBiol
}

J R Soc Med 2005;98:181-182

In early 1968 , I was selected to serve as medical officer and still photographer for an expedition to West Pakistan departing in October of that year. It was sponsored jointly by the Smithsonian Institution, the US Navy and the California Academy of Sciences, and our official mission was to perform field studies and, if possible, return with living examples of the side-swimming sightless dolphin Platinista gangetica. Unofficially the Navy was interested in the biosonar-related abilities of these mammals to detect and discriminate objects within their murky silt-laden aquatic environment.

On arrival at our field-study site on the banks of the Indus River in Baluchistan, I instructed our kitchen personnel to boil all water for drinking and food preparation. Our water supply was continually subjected to faecal contamination by water buffalo, scavenging pariah dogs, and human beings and I was also concerned about cutaneous schistosomiasis. However, the prevailing temperatures were so high that the cooking staff could not be persuaded fully to comply. In late November we completed our mission satisfactorily by returning to San Francisco with three young female dolphins and began to study their biosonar. ${ }^{1}$

Two years later, in October 1970, at the age of 36, I experienced alarming symptoms suggestive of myocardial ischaemia. My electrocardiogram and creatine phosphokinase values were normal; however, sonographic scans revealed multiple filling defects scattered throughout my liver. One of the physicians, suspecting amoebic abscesses, planned to do a percutaneous liver biopsy. I intervened, declaring that if the cysts contained viable Echinococcus granulosus there was a substantial risk that the procedure would cause dangerous leakage of the contents into the peritoneal cavity. A Casoni skin test was ordered and proved unequivocally positive. An exploratory laparotomy, as well as confirming the presence of two liver cysts, showed the spleen to be infarcted and adherent to the diaphragm. The two cysts were injected with formol-saline, drained, and excised with surrounding liver parenchyma; the spleen was removed and the diaphragm was repaired with rectus muscle. The surgeons tried to aspirate a third area in the right hepatic lobe but it yielded nothing.

La Primavera Farm, 33422 Highway 128, Cloverdale, CA 95425-9428, USA

E-mail: FredFrye@aol.com
Pathological examination confirmed the presence of invaginated 'daughter' protoscolices embedded in the wall of each of the two hepatic endocysts. The aetiology of the splenic infarct was unclear.

In 1975, five years postoperatively, I had a further laparotomy for bowel obstruction due to adhesions. At that time the soft area in the right lobe of the liver was reexplored, again to no avail. For the next twenty-six years I enjoyed good health; then, while working on the family farm in April, 2001, I fell from a log and suffered bluntforce trauma to my belly. The next day, a CT scan at the local hospital disclosed multiple fluid-filled lesions throughout the liver and left kidney. The largest hepatic cyst measured $12 \mathrm{~cm}$ in diameter. I then embarked on a course of oral albendazole ( $550 \mathrm{mg}$ twice daily) but two years later this cyst had grown to $20 \mathrm{~cm}$ (Figure 1) and I was again experiencing pain in the region of the right hepatic lobe. Much of the hepatic parenchyma was now occupied by these fluid-filled cystic structures. Because of the potential for further parenchymal compression, CT-guided percutaneous drainage of all approachable hepatic cysts was proposed. In May, 2003, I was admitted for this purpose, but radiology revealed that the contents of the cysts were too heterogeneous and flocculant to permit simple needle aspiration. Open endocyst drainage was planned for some future date. At that point one of my former students, an international authority on echinococcosis, took an interest in my case along with experienced colleagues from the USA and Italy. Their recommendation was that I should take three 21-day courses of the anticestodal helminthicide praziquantel, separated by intervals of 21 days, along with the albendazole I had been taking since 2001. The praziquantel regimen was based on a report from Chawla and others. ${ }^{2}$ Alas, again there was no diminution of endocyst size or volume.

The failure of these anticestodal drugs to induce shrinkage may have been due to the enormous size of the largest cysts and their thick walls, both of which might have prevented achievement of an effective drug concentration within. At present I feel physically fit, albeit with a somewhat gravid shape to my upper belly. The possibility of further surgery does not appeal.

Echinococcosis is not a common parasitic disease in the western world. Most often it is associated with direct or 


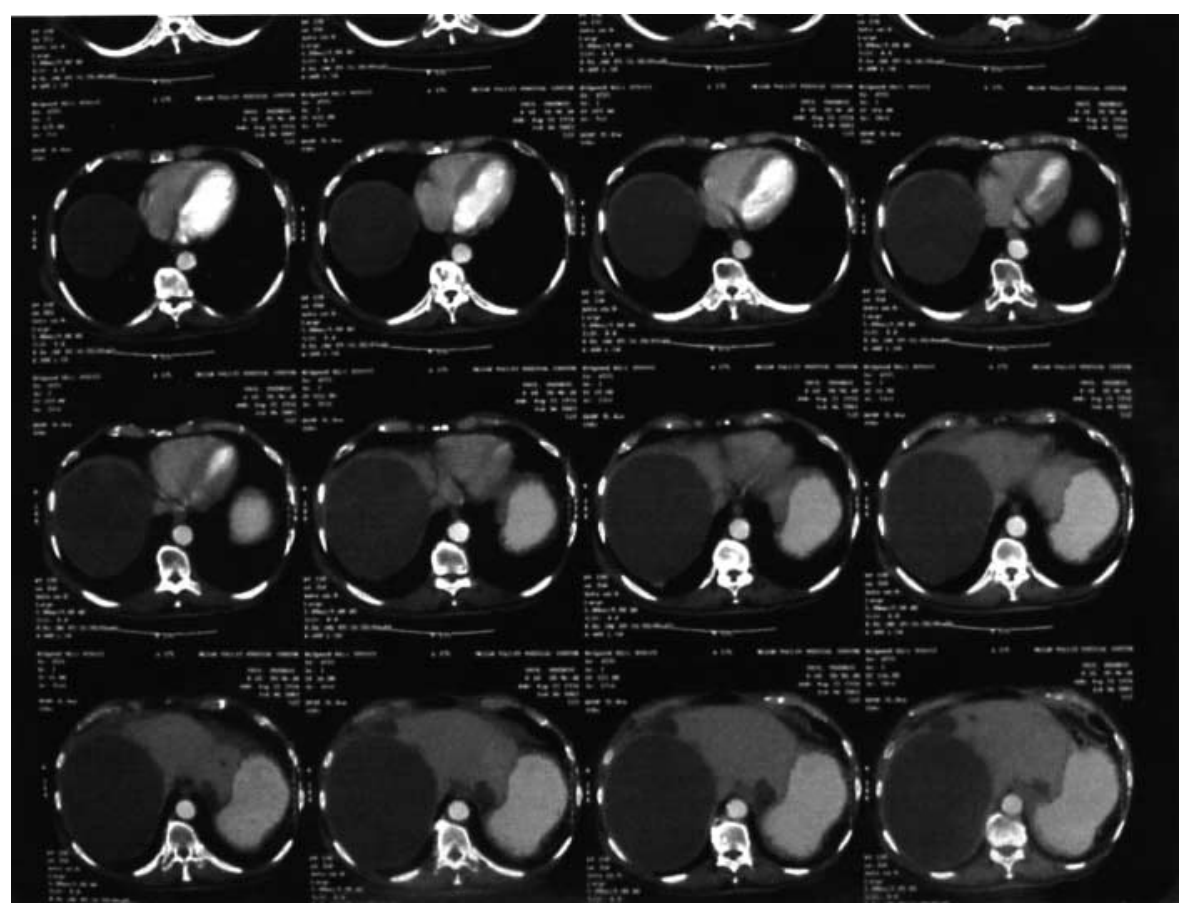

Figure 1 Intravenous contrast CT images obtained in February, 2003. Fluid-filled cyst occupies most of right hepatic lobe

indirect contact with infected canids that serve as the definitive hosts for this multihost cestode parasite. When protoscolices-containing viscera or offal, particularly the liver and lungs, of infected ruminants is ingested by herding dogs or other canines, the cestodes mature into small adults which pass ova into the carnivores' faeces. Humans become accidentally infected when they ingest tapeworm ova from infected canids. The origin of my uninvited guest? I suspect it was the ever-present pariah dogs that came down to the shores of the Indus River in 1968 and contaminated our water supply.

Acknowledgments I am grateful to the following colleagues who have taken an active and intense interest in this case: Edil Wakil MD; Peter Schantz VMD PhD; Larry Falk MD; Guy Teran MD; Charles H Lithgow MD; Gary Ballard MD; Laura Winkler MD; Enrico Brunetti MD PhD. Dr Jason Trent made constructive comments on this paper.

\section{REFERENCES}

1 Herald ES, Brownell RL Jr, Frye FL, Morris EJ, Evans EE, Scott AB. Blind river dolphin, first side-swimming cetacean. Science 1969;166: $1408-10$

2 Chawla A, Maheshwari M, Parmar H, Hira P, Hanchate V. Imaging features of disseminated peritoneal hydatidosis before and after medical treatment. Clin Radiol 2003;58:818-20 